九州大学学術情報リポジトリ

Kyushu University Institutional Repository

\title{
A case of multiple system atrophy-parkinsonian type with stuttering- and palilalia-like dysfluencies and putaminal atrophy
}

Kikuchi, Yoshikazu

Department of Otorhinolaryngology, Graduate School of Medical Sciences, Kyushu University :

Assistant Professor

Umezaki, Toshiro

Voice and Swallowing Center, Fukuoka Sanno Hospital

Uehara, Taira

Department of Neurology, Graduate School of Medical Sciences, Kyushu University

Yamaguchi, Hiroo

Department of Neurology, Graduate School of Medical Sciences, Kyushu University

他

http://hdl. handle. net/2324/4355483

出版情報：Journal of Fluency Disorders. 57，pp.51-58，2018-09-01. Elsevier バージョン：

権利関係 : 
1 A case of multiple system atrophy-parkinsonian type with stuttering- and palilalia-like

2 dysfluencies and putaminal atrophy

3

4 Yoshikazu Kikuchi ${ }^{\mathrm{a}}$, Toshiro Umezaki ${ }^{\mathrm{b}, \mathrm{c}}$, Taira Uehara ${ }^{\mathrm{d}, \mathrm{e}}$, Hiroo Yamaguchi ${ }^{\mathrm{d}}$,

$5 \quad$ Koji Yamashita ${ }^{\mathrm{e}}$, Akio Hiwatashi ${ }^{\mathrm{e}}$, Motohiro Sawatsubashi ${ }^{\mathrm{a}}$, Kazuo Adachi ${ }^{\mathrm{b}}$,

6 Yumi Yamaguchi ${ }^{a}$, Daisuke Murakami ${ }^{\text {a }}$, Jun-ichi Kira ${ }^{\mathrm{d}}$, Takashi Nakagawa ${ }^{\mathrm{a}}$

7

$8 \quad{ }^{a}$ Department of Otorhinolaryngology, Graduate School of Medical Sciences, Kyushu

9 University, Fukuoka, Japan

$10{ }^{\mathrm{b}}$ Voice and Swallowing Center, Fukuoka Sanno Hospital, Fukuoka, Japan

$11{ }^{\mathrm{c}}$ International University of Health and Welfare, Fukuoka, Japan

$12{ }^{\mathrm{d}}$ Department of Neurology, Graduate School of Medical Sciences, Kyushu University,

13 Fukuoka, Japan

$14{ }^{\mathrm{e}}$ Department of Clinical Radiology, Graduate School of Medical Sciences, Kyushu

15 University, Fukuoka, Japan

16

17 Financial Disclosures: This work was supported by the Japan Agency for Medical Research and Development (to Y. K.) and Grant-in-Aid for Young Scientists (B) (17K16922) (to Y. K.). 
1 Conflicts of Interest: The authors have no conflicts of interest to declare.

2

3 Corresponding author:

$4 \quad$ Yoshikazu Kikuchi, MD, PhD

5 Department of Otorhinolaryngology, Graduate School of Medical Sciences, Kyushu

6 University

7 3-1-1 Maidashi, Higashi-ku, Fukuoka 812-8582, Japan

$8 \quad$ Tel.: $+81-92-642-5668$

$9 \quad$ Fax: $+81-92-642-5685$

10 E-mail: kikuci@med.kyushu-u.ac.jp

12 A case of multiple system atrophy-parkinsonian type with stuttering- and palilalia-like

13 dysfluencies and putaminal atrophy

15 Abstract

Both developmental and acquired stuttering are related to the function of the basal

17 ganglia-thalamocortical loop, which includes the putamen. Here, we present a case of

18 stuttering- and palilalia-like dysfluencies that manifested as an early symptom of multiple

19 system atrophy-parkinsonian type (MSA-P) and bilateral atrophy of the putamen. The patient 
1 was a 72-year-old man with no history of developmental stuttering who presented with a stutter

2 for consultation with our otorhinolaryngology department. The patient was diagnosed with

3 MSA-P based on parkinsonism, autonomic dysfunction, and bilateral putaminal atrophy

4 revealed by T2-weighted magnetic resonance imaging. Treatment with levodopa improved

5 both the motor functional deficits related to MSA-P and stuttering-like dysfluencies while

6 reading; however, the palilalia-like dysfluencies were much less responsive to levodopa therapy.

7 The patient died of aspiration pneumonia two years after his first consultation at our hospital.

8 In conclusion, adult-onset stuttering- and palilalia-like dysfluencies warrant careful

9 examination of the basal ganglia-thalamocortical loop, and especially the putamen, using

10 neuroimaging techniques. Acquired stuttering may be related to deficits in dopaminergic

11 function.

13 Keywords: neurogenic stuttering, L-dopa, parkinsonism, putamen, basal ganglia

15 Abbreviations: BGTC loop, basal ganglia-thalamocortical loop; CVA, cerebrovascular

16 accident; MRI, magnetic resonance imaging; MSA-P, multiple system atrophy, Parkinsonian

17 type; PD, Parkinson's disease; SLD, stuttering-like dysfluency; T2WI, T2-weighted imaging;

18 TBI, traumatic brain injury; UPDRS, Unified Parkinson's Disease Rating Scale. 
1

2 Neurogenic stuttering is an acquired speech disorder that typically affects adults with neurological disease; such stuttering is most often associated with cerebrovascular accident (CVA) (Theys et al., 2011, 2013; Tani and Sakai 2010, 2011; Jokel, De Nil, and Sharpe, 2007; Grant et al., 1999; Ardila and Lopez 1986; Helm-Estabrooks, 1986; Helm et al., 1978; Rosenfield, 1972), traumatic brain injury (TBI) (Strasberg et al., 2016; Jokel et al., 2007; HelmEstabrooks and Hotz, 1998; Ludlow et al., 1987), and neurodegenerative disease (Koller, 1983; Leder, 1996). TBI and CVA are easily diagnosed as causes of neurogenic stuttering; TBI is normally reported after a traumatic event, and CVAs such as brain infarction can be diagnosed in early stages using diffusion-weighted imaging (Minematsu et al., 1992), while brain hemorrhages can be diagnosed with computed tomography (Tohgi et al., 1981). In contrast, stuttering accompanying neurodegenerative disease is frequently overlooked or misdiagnosed, especially in early stages of the disease.

To some degree, the phenomenology of stuttering resembles that of a gait disorder in Parkinson's disease (PD). PD is a disorder that involves the basal ganglia, and gait in patients with PD is typically characterized by small steps (i.e., reduced stride length) and lower cadence associated with reduced gait speed, together with festination and freezing (i.e., difficulty in gait initiation or stopping when turning or approaching an obstacle) (Giladi et al., 1992). Visual (e.g., floor markers) or auditory (e.g., metronome) cueing can improve gait performance in 
1 patients with PD (Suteerawattananon et al., 2004; Lim et al., 2005). Similarly, stuttering is also

2 improved by use of a metronome or other external auditory cueing (Brady, 1969; Toyomura et

3 al., 2011). Recently, the cortico-basal ganglia-cortical network was implicated as a neural

4 substrate of both acquired stuttering (Theys et al., 2013) and developmental stuttering (Sitek et

5 al., 2016; Yang et al., 2016; Toyomura et al., 2015; Chang et al., 2016, 2013; Craig-McQuaide

6 et al., 2014; Ingham et al., 2013). In developmental stuttering, putaminal neuropathology

7 appears to underlie the disorder (Ingham et al., 2013; Beal et al., 2013; Jiang et al., 2012;

8 Toyomura et al., 2011, 2015; Chang et al., 2009; Lu et al., 2010; Alm, 2004). Putaminal atrophy

9 has been reported in Parkinson-plus syndromes such as multiple system atrophy-parkinsonian

10 type (MSA-P) (Schrag et al., 1998; Feng et al., 2015). MSA-P is characterized by parkinsonism

11 (bradykinesia, rigidity, irregular jerky tremor, and postural instability), as well as autonomic

12 failure in the form of bladder dysfunction (including early urinary incontinence) and/or

13 orthostatic hypotension (Gilman et al., 2008). Here, we describe a case of adult-onset stuttering

14 associated with MSA-P and bilateral putaminal atrophy diagnosed using magnetic resonance

15 imaging (MRI).

2. Case presentation

The patient was a 72-year-old right-handed man with no history of stuttering. At the 
1 the time at which he first noticed his stuttering. He went to a hospital complaining of only the

2 stutter and underwent diagnostic MRI, but no abnormalities were detected. However, at the age

3 of 71 years, he noticed a tremor of the hands and abnormal gait (short steps and difficulty

4 changing direction). Thereafter, he went to another hospital to receive a second opinion, but,

5 once again, there were no abnormal findings on MRI. At the age of 72 years, the patient read a

6 newspaper advertisement about consultation for stuttering and visited our department. His

7 speech was characterized by repetitions and blocks. He also presented with hand and tongue tremors, and it was suggested that he undergo MRI for suspected basal ganglia abnormalities. MRI revealed bilateral atrophy of the putamen and hyperintensity of the putaminal

10 rims on T2-weighted imaging (T2WI; Figure 1). Our patient showed an average putamen:

11 caudate volume ratio of 1.24 (right 1.43, left 1.07); based on the ratio values reported by Shin

12 et al. (2007), MSA-P was suspected. The patient was then referred to the Department of

13 Neurology for consultation and was admitted. Upon examination by a neurologist, the patient

14 exhibited parkinsonian symptoms (rigidity of the extremities and body trunk, bradykinesia,

15 irregular jerky tremor of the hands and tongue, postural instability, micrographia, hypophonia,

16 retropulsion, difficulty changing direction, and abnormal gait [stooped posture, wide-based and

17 small steps, and reduced arm swing]) and other findings (dysdiadochokinesia, hyperactive

18 perioral and jaw jerk reflex, hyperactive deep tendon reflexes). The patient also exhibited 
1 dysfunction, and impaired sweating [abnormal quantitative sudomotor axon reflex test results]).

2 The patient also presented with impaired smooth pursuit eye movements, limited upgaze but

3 normal downgaze, dysmetria and intention tremor on finger-nose and heel-knee-shin tests, and

4 mild cognitive impairment (Frontal Assessment Battery score of 7 and Mini-Mental State

5 Examination score of 25). Myocardial scintigraphy with I-123 metaiodobenzylguanidine

6 revealed no abnormal scores in early- and delayed-phase imaging. The patient's treatment course is summarized in Figure 2. After his consultation at the

8 Department of Neurology, the patient was treated for MSA-P with L-DOPA/carbidopa (L-

9 DOPA $100 \mathrm{mg} /$ day); the dose of L-DOPA was increased about 6 weeks later (L-DOPA 300

$10 \mathrm{mg} /$ day) and again 1 week after that (L-DOPA $600 \mathrm{mg}$ /day). L-DOPA at a dose of $600 \mathrm{mg} /$ day

11 caused the patient to have trouble sleeping; hence, the dose was decreased to $450 \mathrm{mg} /$ day. (UPDRS) part-III (Fahn, Elton, \& Members of the UPDRS Development Committee, 1987).

The UPDRS is used to rate the severity of various common areas of impairment in PD; part-III is a motor examination containing 27 items that are each scored from 0 (normal) to 4 (severe disability), with a range of total possible scores from 0 (normal) to 108 (severely impaired). Our patient's UPDRS part-III score was 46 with L-DOPA/carbidopa (L-DOPA $100 \mathrm{mg}$ /day), and decreased to 29 when the dose of L-DOPA was increased to $450 \mathrm{mg} /$ day. No UPDRS part- 
1

The patient's "stuttering" was not completely typical; hence, stuttering-like dysfluencies (SLDs) of this patient were evident through repetitions of sounds, syllables, monosyllabic words and prolongations or blocks (dysfluencies typical of stuttering), as well as repetition of whole words or phrases (palilalia-like dysfluency), while reading sentences from Jack and the Beanstalk. The frequency of SLDs was calculated as a percentage by dividing the number of stuttering occurrences by the number of segments (Moriyama et al., 1981). The proportion of presented SLDs was $13.1 \%$ (2.4\% for syllable repetitions, $8.3 \%$ for whole word repetitions, and $2.4 \%$ for blocks) before medication, $10.7 \%(1.2 \%$ for syllable repetitions and 9.5\% for whole-word repetitions) with L-DOPA/carbidopa $300 \mathrm{mg} / \mathrm{day}, 4.8 \%$ (4.8\% for wholeword repetitions) with L-DOPA/carbidopa $600 \mathrm{mg} /$ day, and $9.5 \%$ (1.2\% for syllable repetitions and $8.3 \%$ for whole-word repetitions) with L-DOPA/carbidopa $450 \mathrm{mg} /$ day (Table 1). The dysfluencies typical of stuttering were improved with L-DOPA/carbidopa doses of 300, 450, and $600 \mathrm{mg} / \mathrm{day}$, but those typical of palilalia only improved with a L-DOPA/carbidopa dose of $600 \mathrm{mg}$ /day. We encountered a reading adaptation effect and no improvement in SLDs during singing. The patient read the same sentences aloud 5 times from Jack and the Beanstalk. SLDs decreased with each reading (first reading, 13.1\%; second, 11.9\%; third, 6.0\%; fourth, 7.1\%; fifth, 8.3\%); they occurred for both functors and content words, and the patient felt no anxiety about dysfluencies. Most dysfluencies did not include the initial syllables of words or phrases. There were no secondary symptoms such as facial grimacing, fist clenching, or eye 
1 blinking. Stuttering persisted throughout the treatment course. The patient died from aspiration

2 pneumonia 2 years after his first visit to the Department of Otorhinolaryngology.

3

4 3. Discussion This is the first report to describe adult-onset stuttering as an early symptom of MSA-

6 P. A detailed evaluation of the basal ganglia on MRI was diagnostically useful in this case.

$8 \quad 3.1$ Neurogenic stuttering as an early symptom of MSA-P The presence of extrapyramidal symptoms indicated that the possible diagnoses were

10 MSA-P, PD, or progressive supranuclear palsy (PSP). Because the patient also had autonomic

11 symptoms, and MRI revealed bilateral putaminal atrophy, the most probable diagnosis was

12 MSA-P. Cardiac sympathetic denervation on myocardial scintigraphy with I-123 metaiodobenzylguanidine would have provided supportive criteria for distinguishing PD from

14 MSA-P (Postuma et al., 2015; Marini et al., 2010); however, our patient did not present with any abnormal scores. Affected downgaze with parkinsonian symptoms would have indicated PSP (Litvan et al., 1996; Chen et al., 2010), but the patient's downgaze was normal. Many healthy elderly subjects have a limited range of upgaze (so-called "Blickerschwernis") but not downgaze (Clark and Isenberg, 2001; Oguro et al., 2004); thus, the patient's eye movements did not indicate PSP. 
1

2

3

4

5

6

7

MSA is a sporadic neurodegenerative disorder that encompasses olivopontocerebellar atrophy, striatonigral degeneration, and Shy-Drager syndrome, all of which were originally described as independent clinicopathological entities (Dejerine and Thomas, 1900; van der Eecken et al., 1960; Shy and Drager, 1960). Pappe et al. (1989) and Nakazato et al. (1990) described glial cytoplasmic inclusions in oligodendroglia as a hallmark of MSA, regardless of clinicopathological phenotype. Watanabe et al. (2002) investigated MSA disease progression and survival and found that the median time from initial symptom onset to combined motor and autonomic dysfunction was 2 years (range, 1-10 years). Median intervals from onset to requiring assistance for walking, confinement to a wheelchair, a bedridden state, and death were $3,5,8$, and 9 years, respectively. In the case presented here, MSA-P was diagnosed 2 years after the onset of stuttering. Accordingly, we suggest that it may be difficult to diagnose MSA in its early stage. Thus, adult-onset speech dysfluencies such as stuttering should be considered as possible early symptoms of basal ganglia disorders.

3.2 MRI for the diagnosis of neurodegenerative disease Neurodegenerative diseases involving neurogenic stuttering can be difficult to diagnose. The diagnosis of PD largely relies on clinician experience, and an accurate diagnosis often requires 3-5 years of follow-up (Wang et al., 2016). The diagnosis of MSA-P has been made easier by advances in MRI. Findings suggestive of MSA-P on T2WI include 
1 hyperintensity of the putaminal rim, putaminal hypointensity, and putaminal atrophy (Schrag

2 et al., 1998); however, the two former signs are not specific to MSA-P (Kraft et al., 1999; Lee

3 et al., 2005). In contrast, putaminal atrophy is highly specific to MSA-P, and has been shown

4 to distinguish MSA-P from PD and healthy control subjects with $92.3 \%$ specificity and $44.4 \%$

5 sensitivity (Feng et al., 2015). To identify possible putaminal atrophy, we measured the

6 putamen: caudate volume ratio, and found our patient had an average ratio of 1.24 (right 1.43,

7 left 1.07). Shin et al. (2007) had measured the putamen: caudate volume ratio, and found that

8 the ratio in MSA $(1.29 \pm 0.28)$ was significantly lower than that in $\operatorname{PD}(1.91 \pm 0.29, \mathrm{p}<0.0001)$.

9 Setting an arbitrary cutoff ratio of 1.6 resulted in about $90 \%$ of patients with MSA falling into

10 the group with the lower ratio, whereas more than $80 \%$ of patients with PD belonged to the

11 other group. In the present case, bilateral putaminal atrophy and hyperintensity of the putaminal

12 rim facilitated a diagnosis of MSA-P.

3.3 Neurogenic stuttering and the basal ganglia-thalamocortical loop grammatical words at a similar rate of occurrence to that of substantive words; 2) repetitions, prolongations, and blocks occur in all word positions; 3) there is a consistency in stuttering behavior in all word positions; 4) the speaker does not appear overly anxious about the 
1 blinking are rarely observed; and 6) an adaptation is not observed (Lundgren, Helm-Estabrooks,

2 \& Klein, 2010; Jokel et al., 2007; Rosenfield, 1972).

3

Our patient presented with five of the six features of neurogenic stuttering, but an adaptation effect was observed. Jokel et al. (2007) considered the adaptation effect to occur if dysfluencies over the three readings decreased by minimum of $30 \%$. Our patient showed a $54.5 \%$ decrease in the third reading compared to that in the first reading at the first visit (with no medication). Thus, according to Jokel et al.'s (2007) criteria, our patient showed the reading adaptation effect. Those with neurogenic stuttering sometimes show the reading adaptation effect, and the absence of the adaptation effect does not seem to be a reliable differential criterion (Theys, van Wieringen, \& De Nil, 2008).

Neurogenic stuttering has been associated with dysfunction of the basal gangliathalamocortical (BGTC) loop, including the putamen and supplementary motor area (SMA) (Alm, 2004). Neurogenic stuttering associated with lesion of the left putamen was reported in one case by Kono et al. (1998), in 1 of 3 cases reported by Heuer et al. (1996), in 2 of 3 cases reported by Ciabarra et al. (2000), and in 5 cases reported by Tani et al. (2011). Neurogenic stuttering was also associated with lesions of the left thalamus has been reported by Van Borsel et al. (2003) and Heuer et al. (1996). Furthermore, stuttering after SMA lesions has been described by Van Borsel (1998). Concurrent with these findings, Alm (2004) proposed that the BGTC loop plays a key role in stuttering via the putamen. The case presented here provides 
1 further evidence for a relationship between stuttering and the BGTC loop via the putamen.

3.4 The effectiveness of L-DOPA in MSA-P

The UPDRS part-III is a reliable scale for rating the severity of parkinsonism in MSA-

5

6

7

8 (1989). Although a poor response to L-DOPA is one of the consensus criteria for the diagnosis

of MSA (Gilman et al., 2008), positive L-DOPA motor responsiveness has been reported in 3375\% of patients with MSA (Colosimo et al., 1995; Wenning et al., 1994, 1995, 2005; Hughes et al. 1992; Fearnley and Lees, 1990; Rajput et al. 1990). This beneficial effect has been found to persist for several years in only $13 \%$ of all patients (Wenning et al., 1994). Because our patient died two years after being diagnosed, the ability to evaluate any such effect was limited.

Positive L-DOPA/carbidopa effects on SLDs despite bilateral putamen atrophy could be due to two reasons. One reason is that dopaminergic treatment probably increases cortical connectivity between prefrontal and premotor areas (Michely et al., 2015; Herz et al., 2014). Thus, improvement of SLDs could be due to dopamine enhancement of these cortical regions and/or the putamen, all of which have been associated with SLDs. The other reason is that the improvement of SLDs was probably related to noradrenaline levels. L-DOPA/carbidopa 
1 increases the blood levels of both dopamine and noradrenaline (Delmas, Rothmann, \& Flesch,

2 2008). Freezing of gait with difficulty initiating step movements in the late phase of PD could

3 be attributed to the loss of noradrenergic neurons in the locus coeruleus and their projections

4 to the frontal lobe (Espay, Lewitt \& Kaufmann, 2014; Ono et al., 2016). The frequency of SLDs

5 in our case also appeared to change according to the L-DOPA/carbidopa dose. Thus, the case

6 presented here suggests a possible relationship between dopamine or norepinephrine function,

$7 \quad$ Parkinsonian symptoms, and stuttering in MSA-P.

8 It is notable that this finding is partly inconsistent with those of previous studies

9 regarding neurogenic stuttering and L-DOPA. L-DOPA treatment has been reported to improve

10 (Koller, 1983; Leder et al., 1996), worsen (Louis et al., 2001; Anderson et al., 1999), or have

11 no effect (Goberman and Blomgen, 2003) on the frequency of SLDs in parkinsonism.

12 Goberman and Blomgen (2003) suggested that speech dysfluency might be related to any

13 changes (increase or decrease) in brain dopamine levels.

Since repetitive speech phenomena have been classified in two categories in past studies (Sterling, 1924; Benke et al., 2000; Benke and Butterworth, 2001; Goberman,

Blomgren \& Metzger, 2010; Brabo, Minett \& Ortiz, 2015), we divided the SLDs into dysfluencies typical of stuttering and those typical of palilalia. Notably, there were significant discrepancies between types in terms of their improvement in response to L-dopa/carbidopa 
1 palilalia-like dysfluencies decreased in response to only the highest L-DOPA/carbidopa dose.

2 Benke et al. (2000) noted that the origin of palilalia seemed to be a disruption of fronto-

3 subcortical circuits at the level of the basal ganglia. It is well known that repetitive speech

4 phenomena appear in patients with dementia (Benke and Butterworth, 2001), and in our case,

5 mild dementia with frontal lobe dysfunction was noted, as revealed by his low Frontal

6 Assessment Battery score. Therefore, we consider the neuroanatomical (i.e., frontal lobe

7 inclusion) differences between stuttering- and palilalia-like dysfluencies to be the substrate

8 underlying the different responses to L-DOPA/carbidopa. Future studies are required to

9 determine the exact role of dopamine and/or norepinephrine and the BGTC loop in neurogenic

10 stuttering.

12 Acknowledgments

Neurology in Kyushu University Hospital, who diagnosed and treated this patient. We would also like to thank Editage (www.editage.jp) for English language editing. 
1

2

3

4

5

6

7

8

9

References

Alm, P.A. (2004). Stuttering and the basal ganglia circuits: a critical review of possible relations. Journal of Communication Disorders, 37, 325-369.

Anderson, J.M., Hughes, J.D., Rothi, L.J., Crucian, G.P., \& Heilman, K.M. (1999).

Developmental stuttering and Parkinson's disease: the effects of levodopa treatment. Journal of Neurology, Neurosurgery, and Psychiatry, 66, 776-778.

Ardila, A., \& Lopez, M.V. (1986). Severe stuttering associated with right hemisphere lesion. Brain and Language, 27, 239-246.

Beal, D.S., Gracco, V.L., Brettschneider, J., Kroll, R.M., \& De Nil, L.F. (2013). A voxelbased morphometry (VBM) analysis of regional grey and white matter volume abnormalities within the speech production network of children who stutter. Cortex, 49 , 2151-2161.

Brady, J.P. (1969). Studies on the metronome effect on stuttering. Behaviour Research and Therapy, 7, 197-204.

Chang, S.E., Kenney, M.K., Loucks, T.M., \& Ludlow, C.L. (2009). Brain activation abnormalities during speech and non-speech in stuttering speakers. Neuroimage, 46, 201-212.

Chang, S.E., \& Zhu, D.C. (2013). Neural network connectivity differences in children who stutter. Brain, 136, 3709-3726. 
1 Chang, S.E., Chow, H.M., Wieland, E.A., \& McAuley, J.D. (2016). Relation between functional connectivity and rhythm discrimination in children who do and do not stutter. Neuroimage: Clinical, 12, 442-450.

Chen, A.L., Riley, D.E., King, S.A., Joshi, A.C., Serra, A., Liao, K., Cohen, M.L., OteroMillan, J., Martinez-Conde, S., Strupp, M., \& Leigh, R.J. (2010). The disturbance of gaze in progressive supranuclear palsy: implications for pathogenesis. Frontiers in neurology, 1, 147.

Ciabarra, A.M., Elkind, M.S., Roberts, J.K., \& Marshall, R.S. (2000). Subcortical infarction resulting in acquired stuttering. Journal of Neurology, Neurosurgery, and Psychiatry, 69, 546-549.

Clark, R.A., \& Isenberg, S.J. (2001). The range of ocular movements decreases with aging. Journal of American Association for Pediatric Ophthalmology and Strabismus, 5, 26-30.

Colosimo, C., Albanese, A., Hughes, A.J., de Bruin, V.M., \& Lees, A.J. (1995). Some specific clinical features differentiate multiple system atrophy (striatonigral variety) from Parkinson's disease. Archives of Neurology, 52, 294-298.

Craig-McQuaide, A., Akram, H., Zrinzo, L., \& Tripoliti, E. (2014). A review of brain circuitries involved in stuttering. Frontiers in Human Neuroscience, 8, 884. 
1 Delmas, G., Rothmann, C., \& Flesch, F. (2008). Acute overdose with controlled-release levodopa-carbidopa. Clinical Toxicology (Philadelphia), 46, 274-277. doi: 10.1080/15563650701352170.

Beck, E.N., Martens, K.A.E., \& Almeida, Q.J. (2015). Freezing of Gait in Parkinson's Disease: An Overload Problem? PLoS One, 10(12), e0144986.

Benke, T., Butterworth., B. (2001). Palilalia and repetitive speech: two case studies. Brain and Language, 78, 62-81.

Benke, T., Hohenstein, C., Poewe, W., \& Butterworth, B. (2000). Repetitive speech in Parkinson's disease. Journal of Neurology, Neurosurgery, and Psychiatry, 69, 319-325.

Brabo, N.C, Minett, T.S.C., Ortiz, K.Z. (2014). Fluency in Parkinson's disease: disease duration, cognitive status and age. Arquivos de neuro-psiquiatria, 72, 344-355.

Espay, A.J., LeWitt, P.A., \& Kaufmann, H. (2014). Norepinephrine deficiency in Parkinson's disease: the case for noradrenergic enhancement. Movement Disorders, 29, 1710-1719.

Fahn, S., Elton, R., \& Members of the UPDRS Development Committee. (1987). Unified Park: Macmillan Health-Care Information.

Fearnley, J.M., \& Lees, A.J. (1990). Striatonigral degeneration. A clinicopathological study. 
1 Feng, J.Y., Huang, B., Yang, W.Q., Zhang, Y.H., Wang, L.M., Wang, L.J., \& Zhong, X.L. (2015). The putaminal abnormalities on 3.0T magnetic resonance imaging: can they separate parkinsonism-predominant multiple system atrophy from Parkinson's disease? Acta Radiologica, 56, 322-328.

Giladi, N., McMahon, D., Przedborski, S., Flaster, E., Guillory, S., Kostic, V., \& Fahn, S. (1992). Motor blocks in Parkinson's disease. Neurology, 42, 333-339.

Gilman, S., Wenning, G.K., Low, P.A., Brooks, D.J., Mathias, C.J., Trojanowski, J.Q., Wood, N.W., Colosimo, C., Dürr, A., Fowler, C.J., Kaufmann, H., Klockgether, T., Lees, A., Poewe, W., Quinn, N., Revesz, T., Robertson, D., Sandroni, P., Seppi, K., \& Vidailhet, M. (2008). Second consensus statement on the diagnosis of multiple system atrophy. Neurology, 71, 670-676.

Goberman, A.M., \& Blomgren, M. (2003). Parkinsonian speech dysfluencies: effects of Ldopa-related fluctuations. Journal of Fluency Disorders, 28, 55-70.

Goberman, A.M., Blomgren, M., Metzger, E. (2010). Characteristics of speech dysfluency in Parkinson disease. Journal of Neurolinguistics 23, 470-478

Grant, A.C., Biousse, V., Cook, A.A., \& Newman, N.J. (1999). Stroke-associated stuttering. Archives of Neurology, 56, 624-627.

Helm, N.A., Butler, R.B., \& Benson, D.F. (1978). Acquired stuttering. Neurology, 28, 11591165. 
1 Helm-Estabrooks, N., \& Hotz, G. (1998). Sudden onset of "stuttering" in an adult: neurogenic or psychogenic? Seminars in Speech and Language, 19, 23-29.

3

4

5

6

7

Helm-Estabrooks, N., Yeo, R., Geschwind, N., Freedman, M., \& Weinstein, C. (1986).

Stuttering: disappearance and reappearance with acquired brain lesions. Neurology, 36, 1109-1112.

Herz, D.M., Siebner, H.R., Hulme, O.J., Florin, E., Christensen, M.S., Timmermann, L. (2014). Levodopa reinstates connectivity from prefrontal to premotor cortex during externally paced movement in Parkinson's disease. Neuroimage, 15, 90:15-23

Heuer, R.J., Sataloff, R.T., Mandel, S., \& Travers, N. (1996). Neurogenic stuttering: further corroboration of site of lesion. Ear, Nose, \& Throat Journal, 75, 161-168.

Hughes, A.J., Colosimo, C., Kleedorfer, B., Daniel, S.E., \& Lees, A.J. (1992). The dopaminergic response in multiple system atrophy. Journal of Neurology, Neurosurgery, and Psychiatry, 55: 10091013.

Ingham, R.J., Wang, Y., Ingham, J.C., Bothe, A.K., \& Grafton, S.T. (2013). Regional brain activity change predicts responsiveness to treatment for stuttering in adults. Brain and Language, 127, 510-519.

Jiang, J., Lu, C., Peng, D., Zhu, C., \& Howell, P. (2012). Classification of types of stuttering symptoms based on brain activity. PLoS One, 7, e39747.

Kempster, P.A., Gibb, W.R., Stern, G.M., \& Lees, A.J. (1989). Asymmetry of substantia nigra 
1

neuronal loss in Parkinson's disease and its relevance to the mechanism of levodopa related motor fluctuations. Journal of Neurology, Neurosurgery, and Psychiatry, 52, 72 76.

Koller, W.C. (1983). Dysfluency (stuttering) in extrapyramidal disease. Archives of Neurology, 40, 175-177.

Kono, I., Hirano, T., Ueda, Y., \& Nakajima, K. (1998). A case of acquired stuttering resulting from striatocapsular infarction. Rinsho Shinkeigaku, 38, 758-761.

Kraft, E., Schwarz, J., Trenkwalder, C., Vogl, T., Pfluger, T., \& Oertel, W.H. (1999). The combination of hypointense and hyperintense signal changes on T2-weighted magnetic resonance imaging sequences: a specific marker of multiple system atrophy? Archives of Neurology, 56, 225-228.

Leder, S.B. (1996). Adult onset of stuttering as a presenting sign in a parkinsonian-like syndrome: a case report. Journal of Communication Disorders, 29, 471-478.

Lee, W.H., Lee, C.C., Shyu, W.C., Chong, P.N., \& Lin, S.Z. (2005). Hyperintense putaminal rim sign is not a hallmark of multiple system atrophy at 3T. American Journal of Neuroradiology, 26, 2238-2242.

Lim, I., van Wegen, E., de Goede, C., Deutekom, M., Nieuwboer, A., Willems, A., Jones, D., Rochester, L., \& Kwakkel, G. (2005). Effects of external rhythmical cueing on gait in patients with Parkinson's disease: a systematic review. Clinical Rehabilitation, 19, 695- 
Litvan, I., Agid, Y., Calne, D., Campbell, G., Dubois, B., Duvoisin, R. C., Goetz, C. G., Golbe, L. I., Grafman, J., Growdon, J. H., Hallett, M., Jankovic, J., Quinn, N. P., Tolosa, E., \& Zee, D. S. (1996). Clinical research criteria for the diagnosis of progressive supranuclear palsy (Steele-Richardson-Olszewski syndrome): report of the NINDSSPSP international workshop. Neurology, 47, 1-9.

Louis, E.D., Winfield, L., Fahn, S., \& Ford, B. (2001). Speech dysfluency exacerbated by levodopa in Parkinson's disease. Movement Disorders, 16, 562-565.

Lu, C., Peng, D., Chen, C., Ning, N., Ding, G., Li, K., Yang, Y., \& Lin, C. (2010). Altered effective connectivity and anomalous anatomy in the basal ganglia-thalamocortical circuit of stuttering speakers. Cortex, 46, 49-67.

Ludlow, C.L., Rosenberg, J., Salazar, A., Grafman, J., \& Smutok, M. (1987). Site of penetrating brain lesions causing chronic acquired stuttering. Annals of Neurology, 22, 60-66.

Lundgren, K., Helm-Estabrooks, N., \& Klein, R. (2010) Stuttering Following Acquired Brain Damage: A Review of the Literature. Journal of Neurolinguistics, 23, 447-454. Villa, G., Abbruzzese, G, Sambuceti, G. (2010) Whole body and cardiac metaiodobenzylguanidine kinetics in Parkinson disease and multiple system atrophy: 

implications for the diagnostic role of imaging. Clinical Nuclear Medicine. 35, 311-316.

Michely, J., Volz, L.J., Barbe, M.T., Hoffstaedter, F., Viswanathan, S., Timmermann, L., Eickhoff, S.B., Fink, G.R., Grefkes, C. (2015). Dopaminergic modulation of motor network dynamics in Parkinson's disease. Brain, 138, 664-678.

Minematsu, K., Li, L., Fisher, M., Sotak, C.H., Davis, M.A., \& Fiandaca, M.S. (1992).

Diffusion-weighted magnetic resonance imaging: rapid and quantitative detection of focal brain ischemia. Neurology 42, 235-240.

Moriyama, H., Ozawa, E., Kunishima, K., Suzuki, N., \& Doi, A. (1981). The Stuttering Test (Version 1). Japan Journal of Logopedics and Phoniatrics, 22, 194-208.

Nakazato, Y., Yamazaki, H., Hirato, J., Ishida, Y., \& Yamaguchi, H. (1990). Oligodendroglial microtubular tangles in olivopontocerebellar atrophy. Journal of Neuropathology \& Experimental Neurology, 49, 521-530.

Oguro, H., Okada, K., Suyama, N., Yamashita, K., Yamaguchi, S., \& Kobayashi, S. (2004). Decline of vertical gaze and convergence with aging. Gerontology, 50, 177-181.

Ono, S.A., Sato, T., \& Muramatsu, S. (2016). Freezing of Gait in Parkinson's Disease Is Associated with Reduced 6-[(18)F]Fluoro-1-m-tyrosine Uptake in the Locus Coeruleus. Parkinsons Disease, 2016, 5430920. doi: 10.1155/2016/5430920. Epub 2016 Feb 23.

Papp, M.I., Kahn, J.E., \& Lantos, P.L. (1989). Glial cytoplasmic inclusions in the CNS of patients with multiple system atrophy (striatonigral degeneration, olivopontocerebellar 
1

atrophy and Shy-Drager syndrome). Journal of the Neurological Sciences, 94, 79-100.

Postuma RB, Berg D, Stern M, Poewe W, Olanow CW, Oertel W, Obeso J, Marek K, Litvan I, Lang AE, Halliday G, Goetz CG, Gasser T, Dubois B, Chan P, Bloem BR, Adler CH, Deuschl G. (2015) MDS clinical diagnostic criteria for Parkinson's disease. Mov Disord. 30, 1591-1601.

Rajput, A.H., Rozdilsky, B., Rajput, A. \& Ang, L. (1990) Levodopa efficacy and pathological basis of Parkinson syndrome. Clinical Neuropharmacology, 13, 553-558.

Rosenfield, D.B. (1972). Stuttering and cerebral ischemia. New England Journal of Medicine, 287, 991.

Schrag, A., Kingsley, D., Phatouros, C., Mathias, C.J., Lees, A.J., Daniel, S.E., \& Quinn, N.P. (1998). Clinical usefulness of magnetic resonance imaging in multiple system atrophy. Journal of Neurology, Neurosurgery, and Psychiatry, 65, 65-71.

Shin, H.Y., Kang, S.Y., Yang, J.H., Kim, H.S., Lee, M.S., Sohn, Y.H. (2007) Use of the Putamen/Caudate Volume Ratio for Early Differentiation between Parkinsonian Variant of Multiple System Atrophy and Parkinson Disease. Journal of Clinical Neurology, 3, $79-81$.

Shy, G.M., \& Drager, G.A. (1960). A neurological syndrome associated with orthostatic hypotension: a clinicalpathologic study. Archives of Neurology, 2, 511-527.

Sitek, K.R., Cai, S., Beal, D.S., Perkell, J.S., Guenther, F.H., \& Ghosh, S.S. (2016). 
Decreased Cerebellar-Orbitofrontal Connectivity Correlates with Stuttering Severity:

Whole-Brain Functional and Structural Connectivity Associations with Persistent Developmental Stuttering. Frontiers in Human Neuroscience, 10, 190.

Sterling, W. (1924). Palilalie et le symptome 'linguosalivaire' dans le Parkinsonisme encephalitique. Revue Neurologique, 32, 205-220.

Strasberg, S., Johnson, E.J., \& Parry, T. (2016). “Stuttering” after minor head trauma. American Journal of Emergency Medicine, 34, 685.e3-4.

Suteerawattananon, M., Morris, G.S., Etnyre, B.R., Jankovic, J., Protas, E.J. (2004). Effects of visual and auditory cues on gait in individuals with Parkinson's disease. Journal of the Neurological Sciences, 15, 219, 63-69.

Tani, T., \& Sakai, Y. (2010). Stuttering after right cerebellar infarction: a case study. Journal of Fluency Disorders, 35, 141-145.

Tani, T., \& Sakai, Y. (2011). Analysis of five cases with neurogenic stuttering following brain injury in the basal ganglia. Journal of Fluency Disorders, 36, 1-16.

Theys, C., van Wieringen, A., Sunaert, S., Thijs, V., \& De Nil, L.F. (2011). A one year prospective study of neurogenic stuttering following stroke: incidence and co-occurring disorders. Journal of Communication Disorders, 44, 678-687.

Theys, C., De Nil, L., Thijs, V., van Wieringen, A., \& Sunaert, S. (2013). A crucial role for the cortico-striato-cortical loop in the pathogenesis of stroke-related neurogenic 
1

stuttering. Human Brain Mapping, 34, 2103-2112.

Theys, C., van Wieringen, A., \& De Nil, L.F. (2008) A clinician survey of speech and nonspeech characteristics of neurogenic stuttering. Journal of Fluency Disorders, 33, 1-23.

Tison, F., Yekhlef, F., Chrysostome, V., Balestre, E., Quinn, N.P., Poewe, W., \& Wenning, G.K. (2002). Parkinsonism in multiple system atrophy: natural history, severity (UPDRSIII), and disability assessment compared with Parkinson's disease. Movement Disorders, 17, 701-709.

Tohgi, H., Mochizuki, H., Yamanouchi, H., Iio, M., Yamada, H., Chiba, K., \& Tomonaga, M. (1981). A comparison between the computed tomogram and the neuropathological findings in cerebrovascular disease. Journal of Neurology, 224, 211-220.

Toyomura, A., Fujii, T., \& Kuriki, S. (2011). Effect of external auditory pacing on the neural activity of stuttering speakers. Neuroimage, $57,1507-1516$.

Toyomura, A., Fujii, T., \& Kuriki, S. (2015). Effect of an 8-week practice of externally triggered speech on basal ganglia activity of stuttering and fluent speakers. Neuroimage, 109, 458-468.

Van Borsel, J., Van Lierde, K., Van Cauwenberge, P., Guldemont, I., \& Van Orshoven, M. (1998). Severe acquired stuttering following injury of the left supplementary motor region: A case report. Journal of Fluency Disorders, 23, 49-58.

Van Borsel, J., van der Made, S., \& Santens, P. (2003). Thalamic stuttering: a distinct clinical 
1

entity? Brain and Language, 85, 185-189.

van der Eecken, H., Adams, R.D., \& van Bogaert, L. (1960). Striopallidal-nigral degeneration. An hitherto undescribed lesion in paralysis agitans. Journal of Neuropathology \& Experimental Neurology, 19, 159-161.

Wang, Z., Luo, X.G., \& Gao, C. (2016). Utility of susceptibility-weighted imaging in Parkinson's disease and atypical Parkinsonian disorders. Translational Neurodegeneration, 5, 17.

Watanabe, H., Saito, Y., Terao, S., Ando, T., Kachi, T., Mukai, E., Aiba, I., Abe, Y., Tamakoshi, A., Doyu, M., Hirayama, M., \& Sobue, G. (2002). Progression and prognosis in multiple system atrophy: an analysis of 230 Japanese patients. Brain, 125, 1070-1083.

Wenning, G.K., Geser, F., \& Poewe, W. (2005). Therapeutic strategies in multiple system atrophy. Movement Disorders, Suppl, 12, S67-76

Wenning, G.K., Ben-Shlomo, Y., Magalhaes, M., Daniel, S.E., \& Quinn, N.P. (1995). Clinicopathological study of 35 cases of multiple system atrophy. Journal of Neurology, Neurosurgery, and Psychiatry, 58, 160-166.

Wenning, G.K., Ben Shlomo, Y., Magalhaes, M., Daniel, S.E., \& Quinn, N.P. (1994). Clinical features and natural history of multiple system atrophy. An analysis of 100 cases. Brain, $117,835-845$.

Yang, Y., Jia, F., Siok, W.T., \& Tan, L.H. (2016). Altered functional connectivity in persistent 
1 developmental stuttering. Scientific Reports, 6, 19128. 
1 Table 1. The proportion of stuttering-like dysfluencies corresponding to the dose of L-

2 DOPA/carbidopa.

3

\begin{tabular}{|c|l|l|l|l|l|}
\hline \multicolumn{2}{|c|}{} & $\begin{array}{l}\text { Before } \\
\text { medication }\end{array}$ & $\begin{array}{l}\text { L- } \\
\text { DOPA/carbidop } \\
\text { a (L-DOPA, 300 } \\
\text { mg/day) }\end{array}$ & $\begin{array}{l}\text { L- } \\
\text { DOPA/carbidop } \\
\text { a (L-DOPA, 600 } \\
\text { mg/day) }\end{array}$ & $\begin{array}{l}\text { L- } \\
\text { DOPA/carbidop } \\
\text { a (L-DOPA, 450 } \\
\text { mg/day) }\end{array}$ \\
\hline $\begin{array}{c}\text { Dysfluency } \\
\text { typical of } \\
\text { stuttering }\end{array}$ & $\begin{array}{l}\text { Syllable } \\
\text { repetitions }\end{array}$ & $2.4 \%$ & $1.2 \%$ & $0 \%$ & $1.2 \%$ \\
\cline { 2 - 7 } $\begin{array}{c}\text { Blocks } \\
\text { Palilalia-like } \\
\text { dysfluency }\end{array}$ & $\begin{array}{l}\text { Whole } \\
\text { word } \\
\text { repetitions }\end{array}$ & $2.4 \%$ & $0 \%$ & $0 \%$ & $0 \%$ \\
\hline Total & $8.3 \%$ & $9.5 \%$ & $4.8 \%$ & $8.3 \%$ \\
\hline
\end{tabular}

4

5

6

7 
$2 \quad$ Figures

3 Figure 1. Bilateral putaminal atrophy and rim hyperintensity on T2WI

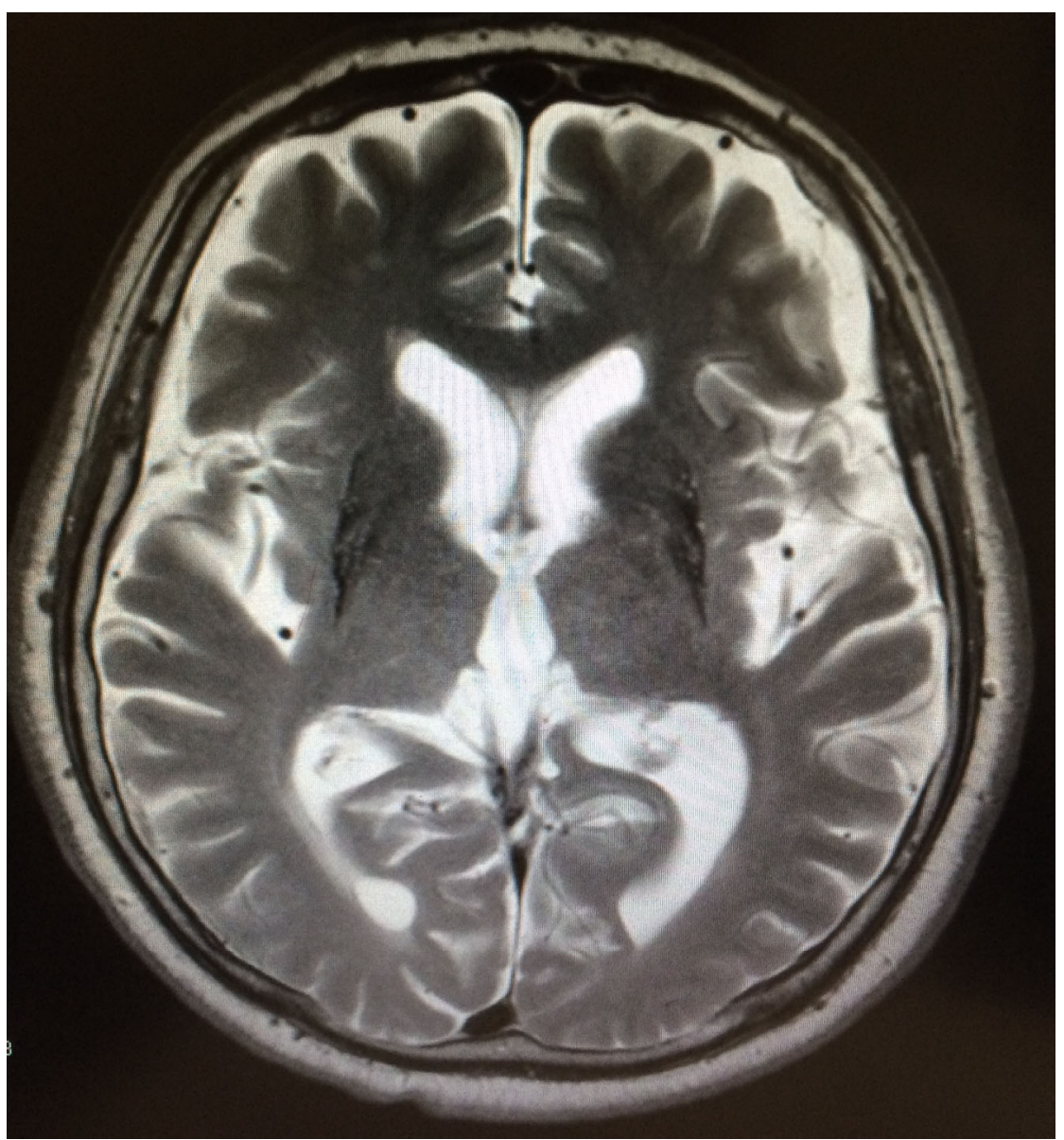


1 Figure 2. The patient's treatment course; UPDRS, Unified Parkinson's Disease Rating Scale;

2 SLD, stuttering-like dysfluency.

\section{Treatment course}

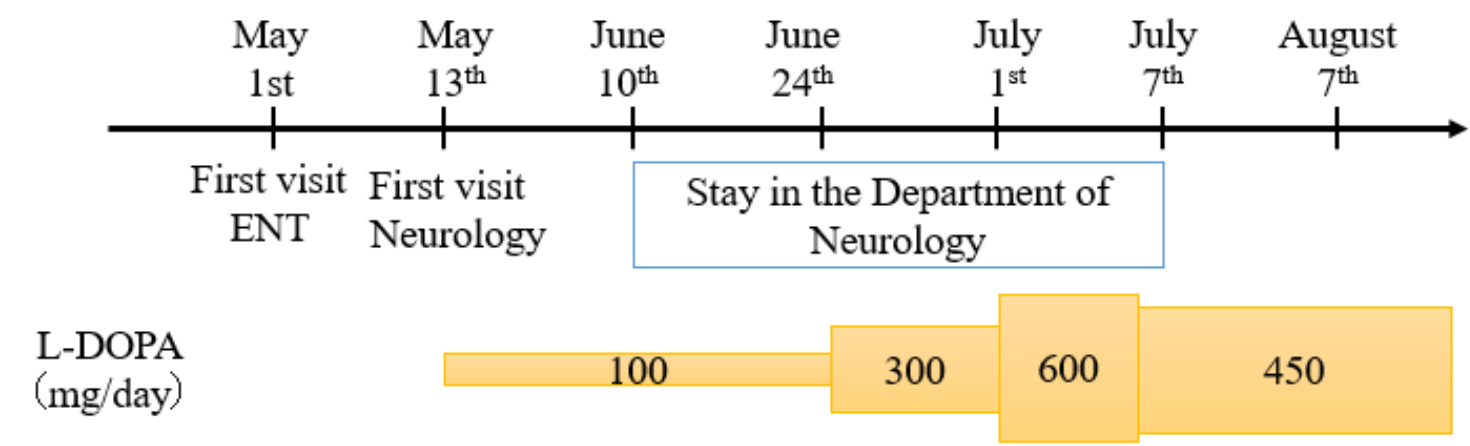

UPDRS PartIII

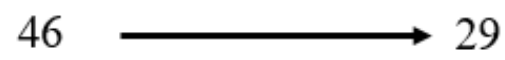

3

SLD (\%)

13.1

10.7

4.8

9.5

4 